\title{
Identification S100A9 as a potential biomarker in neuroblastoma
}

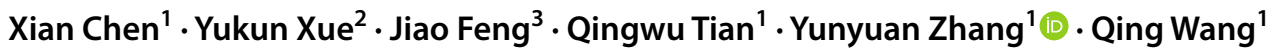

Received: 3 July 2021 / Accepted: 15 September 2021 / Published online: 24 October 2021

(c) The Author(s) 2021

\begin{abstract}
Background More than half of Neuroblastoma (NB) patients presented with distant metastases and the relapse of metastatic patients was up to $90 \%$. It is urgent to explore a biomarker that could facilitate the prediction of metastasis in NB patients. Methods and results In the present study, we systematically analyzed Gene Expression Omnibus datasets and focused on identifying the critical molecular networks and novel key hub genes implicated in NB metastasis. In total, 176 up-regulated and 19 down-regulated differentially expressed genes (DEGs) were identified. Based on these DEGs, a PPI network composed of 150 nodes and 452 interactions was established. Through PPI network identification combined with qRT-PCR, ELISA and IHC, S100A9 was screened as an outstanding gene. Furthermore, in vitro tumorigenesis assays demonstrated that S100A9 overexpression enhanced the proliferation, migration and invasion of NB cells.

Conclusions Taken together, our findings suggested that S100A9 could participate in NB tumorigenesis and progression. In addition, S100A9 has the potential to be used as a promising clinical biomarker in the prediction of NB metastasis.
\end{abstract}

Keywords Neuroblastoma $\cdot$ Bioinformatics analysis $\cdot$ S100A9 $\cdot$ Metastasis $\cdot$ Biomarker

\section{Introduction}

Neuroblastoma (NB), the most aggressive form of solid tumor of infants, accounting for $15 \%$ of cancer deaths in children $[1,2]$. Until now, the main preferred treatment choices still remain surgery, chemotherapy and radiotherapy, which inevitably lead to tremendous toxicity and drug resistance. For high-risk NB patients, the recurrence and progression ratio are about $50 \%$ [3]. Thus, it is urgent for us to identify new effective biomarker for early diagnosis, metastasis prediction and ideal therapeutic target for NB patients.

Yunyuan Zhang and Qing Wang have contributed equally to this work.

Yunyuan Zhang

hellozyycool@163.com

Qing Wang

wangqing0533@aliyun.com

1 Department of Clinical Laboratory, The Affiliated Hospital of Qingdao University, Qingdao 266003, Shandong, China

2 Department of Clinical Laboratory, Pingyi Hospital of Traditional Chinese Medicine, Linyi 273300, Shandong, China

3 Department of Pathology, The Affiliated Hospital of Qingdao University, Qingdao 266003, Shandong, China
S100A9, which is also called calgranulin B or migration inhibitory factor-related protein 14 (MRP-14), belongs to the low-molecular-weight calcium-binding S100 protein family [4]. Evidence has shown that S100A9 protein is elevated in metastatic melanoma and prostate cancer $[5,6]$. In these tumors, increased expression of S100A9 was correlated with tumorigenesis and poor differentiation. Although S100A9 have been studied in many types of cancers, the biological function in malignancies was still remains contradictory and poorly understood. For example, elevated S100A9 in malignant tissues were associated with significantly shorter cancer survival, while downregulated S100A9 is correlated with tumor proliferation, inflammation invasion and angiogenesis [7-13]. To our knowledge, this is the first research to investigate the effects of S100A9 in NB patients.

In the present study, bioinformatic analysis was performed based on the GEO database [14]. After DEGs screening and functional analysis, PPI net-work of DEGs were further analyzed. And we found that the expression of S100A9 is pretty high in metastatic NB patients. In addition, we investigated the biological functions of S100A9 in NB cell line. These results may help us identify new effective biomarker for early diagnosis, metastasis prediction and ideal therapeutic target for NB patients, and provide valuable biological information for further investigation of NB. 


\section{Materials and methods}

\section{Bioinformatic analysis}

\section{Data processing and analysis}

The public microarray dataset GSE90121, which was obtained based on the Affymetrix GPL570 platform (Affymetrix Human Genome U133 Plus 2.0 Array), was downloaded from the Gene expression omnibus (GEO) database (http://www.ncbi.nlm.nih.gov/geo/) [14]. This dataset was deposited by David Kaplan et al., containing information from human NB SK-N-AS metastatic subpopulations isolated after in vivo selection, aimed to identify genomic signatures that regulate metastasis and candidate therapeutics for NB patients. A total of 16 samples, including 12 metastatic samples and four primary samples, were enrolled in the current dataset. Robust multi-array average (RMA) affy package of Bioconductor was used to adjust the raw data. The processed gene expression data was then filtered to include those probe sets with annotations which reference the new version annotation files. To identify DEGs, we used the Linear Models (Microarray Data package in Bioconductor) to compare the expression levels of genes between the metastatic group and the localized tumor group [15]. An adjusted p-value of $<0.05$ and a $\mid \log 2 \mathrm{FC}$ (fold change) । of $\geq 2$ was used as the threshold.

\section{Functional enrichment analysis of DEGs}

Database for annotation, visualization and integrated discovery (DAVID) integrates a set of functional enrichment tools to distinguish functional genes underlying diseases processing (http://david.abcc.ncifcrf.gov/) [16]. Gene ontology (GO) function and Kyoto Encyclopedia of Genes and Genomes (KEGG) pathway enrichment analyses of DEGs were performed based on DAVID. $P$ value $<0.05$ and count $\geq 2$ was regarded as statistically significant differences.

\section{Protein-protein interaction network construction by STRING}

We used the Search Tool for the Retrieval of Interacting Genes (STRING), an online tool and biological database for prediction of interactions between proteins, to construct the PPI network [17]. According to our analysis based on STRING, score (median confidence) $>0.15$ was the standard of PPIs for DEGs selections. The Cytoscape software was used to visualize the PPI network [18]. The proteins that have many interaction partners, were defined as the hub proteins, constituting the extremely important nodes in the
PPI network. To identify such hub proteins in the PPI network, we utilized six bioinformatic tools, namely Closeness, Degree, EPC, MNC, Radiality and Stress centrality. Subnetwork analysis was then conducted to help us discover the outstanding genes.

\section{NB patients, tissue samples and cell lines}

Primary tumor tissues were obtained from 9 NB patients with bone marrow metastasis and 10 NB patients without bone marrow metastasis who had undergone tumor resection surgery at the Affiliated Hospital of Qingdao University. None of the included patients was treated with chemotherapy, hormonal therapy or radiotherapy before the tumor resection surgery. Written informed consent was obtained from all the participants. The current research was conducted with the permission of the Medical Ethical Committee of Affiliated Hospital of Qingdao University (Qingdao, China).

Human NB cell line SH-SY5Y was kindly provided by Professor Xiao from the Guizhou Medical University. The cells were cultured in Dulbecco's modified Eagle's medium (DMEM) contained 10\% fetal bovine serum (FBS, Hyclone, USA) under the conditions of $37{ }^{\circ} \mathrm{C}, 5 \% \mathrm{CO}_{2}$.

\section{Quantitative real-time PCR}

The expression of $T A C 1, P T G S 2$ and $F G F 1$ was examined by quantitative real-time reverse transcription polymerase chain reaction (qRT-PCR). The collected tissues were immediately frozen at $-80^{\circ} \mathrm{C}$ after surgery. Total RNA was extracted from cancer tissues by TRIzol reagent (Invitrogen Life Technologies). Then the extracted RNA was transcribed into cDNA using random primers and analyzed with an ABI 7000 Real-Time PCR System (Applied Biosystems). PCR primers were as following: TAC1 primers: (forward) 5'-TGA TCT GAA TTA CTG GTC CGA CT-3' and (reverse) 5'-TCC GGC AGT TCC TCC TTG A-3'; PTGS2 primers: (forward) 5'-TAA GTG CGA TTG TAC CCG GAC-3' and (reverse) 5'-TTT GTA GCC ATA GTC AGC ATT GT-3'; FGF1 primers: (forward) 5'-CTC CCG AAG GAT TAA ACG ACG-3' and (reverse) 5'-GTC AGT GCT GCC TGA ATG CT-3'; GAPDH primers (forward) 5'-CAG CGA CAC CCA CTC CTC-3' and (reverse) 5'-TGA GGT CCA CCA CCC TGT-3'. Reactions were performed in triplicate using SYBR Green master mix (TaKaRa, Japan) and normalized to GAPDH mRNA level using the $\Delta \Delta \mathrm{Ct}$ method.

\section{NB serum samples and ELISA}

After blood samples centrifuged at $3000 \times g$ for $10 \mathrm{~min}$ at $4{ }^{\circ} \mathrm{C}$, the serum samples were aliquoted and stored at $-80^{\circ} \mathrm{C}$ until further processing. To quantify levels of S100A9 in 
serum, ELISA was performed as previously described [19]. By using human S100A9 (JYM0539Hu, JYM, China) ELISA kits, S100A9 in serum of the NB patients were detected according to the manufacturer's recommended procedure.

\section{IHC staining}

In brief, the formalin fixed, paraffin-embedded tissues sections were deparaffinized, rehydrated and boiled in $0.01 \mathrm{M}$ citrate buffer for $10 \mathrm{~min}$, then incubated with $0.3 \% \mathrm{H}_{2} \mathrm{O}_{2}$ in methanol to block endogenous peroxidase activity. Then the sections were incubated with the anti-S100A9 antibody (Cell Signaling Technology, USA), followed by incubation with secondary antibody tagged with the peroxidase enzyme for $30 \mathrm{~min}$ at room temperature, finally visualized with $0.05 \%$ DAB (3,3'-diaminobenzidine) until the desired brown reaction product was obtained. All slides were observed under an OLYMPUS BX41 Microscope, and representative photographs were taken.

\section{Construction of plasmids and establishment of stably transfected cells}

SBI-piggyBac vector, GST-S100A9, were kindly provided by Professor T.C. He from the University of Chicago. To construct an S100A9 overexpression plasmid, the complete coding sequence of human S100A9 gene was subcloned into the SBI-piggyBac vector. For S100A9 silencing, siRNAs targeting human S100A9 with the sequences of 5'- GCA AGA CGA TGA CTT GCA A -3' and 5'- TTG CAA GTC ATC GTC TTG $C-3^{\prime}$ ' were synthesized and assembled into the SBI-piggyBac vector, resulting in SBI-siS100A9. After transfecting SH-SY-5Y NB cells with the constructed plasmids, the stably transfected cells were selected by incubation with puromycin for one week. The stable transfected cell lines, namely Control (SH-SY5Y transfected with SBI empty vector), S100A9 (SH-SY5Y transfected with SBIS100A9) and siS100A9 (SH-SY5Y transfected with SBIsiS100A9) briefly.

\section{Cell viability assay}

The viability of SH-SY5Y cells was assessed by 3-(4,5-dimethylthiazol-2-yl)-2, 5-diphe-nyltrazolium bromide (MTT) assay. Briefly, stably transfected SH-SY5Y cells were seeded in 96-well plates (1000 cells/well). The cells were incubated in DMEM supplemented with $1 \%$ FBS for 24, 48, 72, 96 and $120 \mathrm{~h}$, then incubated with MTT reagent (Progema, Madison, WI, USA, $20 \mu \mathrm{L} /$ well) for another $4 \mathrm{~h}$ at $37^{\circ} \mathrm{C}$ to allow the formation of formazan. After that, $100 \mu \mathrm{L}$ of dimethyl sulfoxide was added into the cell culture medium for another 10-min incubation at room temperature.
At last, in every day of the next five days, a microplate reader (Bio-rad, iMark) was used to measure the absorbance at $492 \mathrm{~nm}$ of each well. Each sample included three independent replicates.

\section{Colony formation assay}

Exponentially growing stably transfected SH-SY5Y cells were seeded at a low density (100 cells/well) in cell culture medium containing $1 \%$ FBS in 6-well plates. The cells were allowed to grow for about 10 days to form colonies. The culture medium was refreshed every 3-4 days. Crystal violet was used to stained the colonies. Colony numbers from 3 wells were used to calculated the average colony number.

\section{Scratch wound healing assay}

The scratch wound healing assay was performed as described previously [20, 21]. Briefly, stably transfected SH-SY5Y cells were seeded in 6-well plates and grown to 90\% confluency. Then, sterile micro-pipette tips were used to scratch the monolayer formed by SH-SY5Y cells to create a wound. After that, the medium (DMEM containing 1\% FBS) was refreshed every day to remove the floating cells. Bright field microscopy was used to monitor the wound healing status at $24 \mathrm{~h}, 48 \mathrm{~h}$, and $72 \mathrm{~h}$ after the wound was created. Each assay was repeated three times. ImageJ software was used to calculate the wound healing ratio.

\section{Transwell invasion assay}

A chamber coated with non-type I-collagen (Millipore, USA) was used for the transwell assay. The upper chamber coated with ECM gel (Sigma, USA) was filled with $400 \mu$ Lof serum-free DMEM and seeded with exponentially growing stably transfected SH-SY5Y cells $\left(1 \times 10^{4}\right.$ cells $)$. The lower chamber was filled with $500 \mu \mathrm{L}$ of DMEM supplemented with $20 \%$ FBS, which served as a chemoattractant. After $24 \mathrm{~h}$ of incubation, the cells migrated across the transwell membrane were dried, fixed with methanol, and then stained with hematoxylin-eosin ( $\mathrm{H}$ and $\mathrm{E})$. Cotton swabs were used to remove the cells on the upper surface of the transwell membrane. At last, an inverted microscope $(\times 100$ magnification) was used to count the number of cells migrated across the transwell membrane. Five randomly-selected fields were examined to obtain the mean value of the number of cells migrated across the transwell membrane. The experiment was repeated three times.

\section{Statistical analysis}

All data are presented as means \pm standard deviations. T test was performed in the GraphPad Prism software to determine 
the statistical significance of differences between groups. A P value of less than 0.05 was considered statistically significant.

\section{Results}

\section{Enrichment analyses of DEGs}

In general, 176 up-regulated DEGs and 19 down-regulated DEGs were identified based on the cut-off criteria ( $p$-value $<0.05$ and count $\geq 2$ ), which were used to generate a heatmap for the NB patients with and without metastasis (Fig. 1A). Functional enrichment analysis revealed that the top 18 mostly enriched GO terms and top two mostly enriched KEGG pathways were associated with regulation of nucleosome assembly, innate immune response in mucosa, extracellular matrix organization, angiogenesis and innate immune response, etc. (Table 1). In addition, volcano plot was able to quick identify the expression changes within the gene sets by combination of statistical tests (adjusted p-value) and magnitude of change (Fig. 1B).

\section{PPI network analysis}

To identify the potential biomarkers that predict metastasis in NB patients, the DEGs were delineated to construct a PPI network. A DEG with a combined score (median confidence) $>0.15$ was regarded as a significantly differentially expressed gene. The Cystoscope software was used to visualize the PPI network. As shown in Fig. 2A, the PPI network constructed by STRING is composed of 150 nodes and 452 interactions. The top 10 hub proteins in the PPI network determined by Closeness, Degree, EPC, MNC, Radiality and Stress centrality are listed in Table 2 . The results showed that TAC1, PTGS2 and FGF1 were the most outstanding genes and maybe play an important role in the NB metastasis. Sub-network analysis suggested that S100A9 was the outstanding hub protein (Fig. 2B).

\section{Validation the outstanding genes in NB patients}

To verify the expression of TAC1, PTGS2 and FGF1 in microarray data, qPCR was performed to detect the expression of those three genes. The qRT-PCR results showed that the expression of three genes were no significant differences

\section{A}

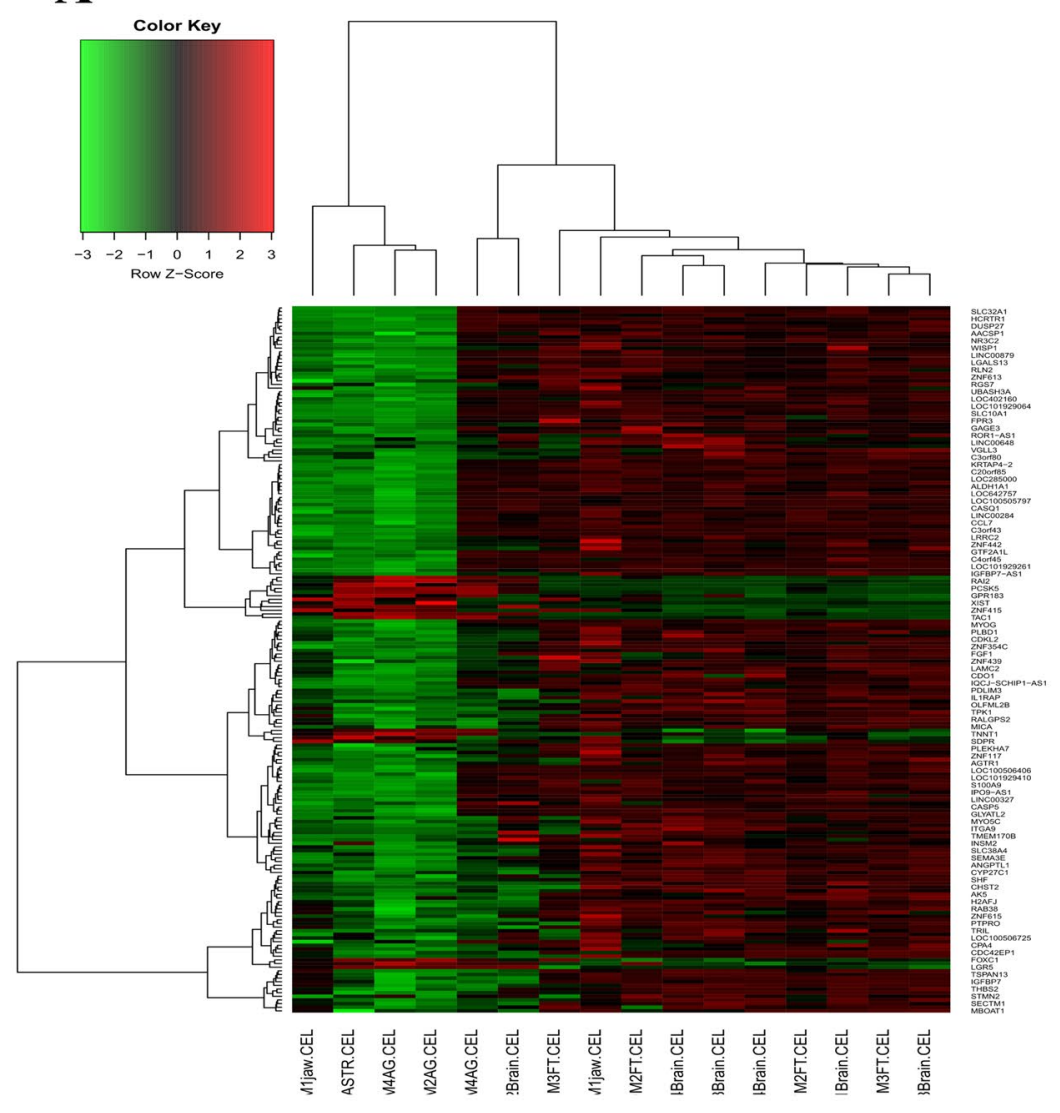

B

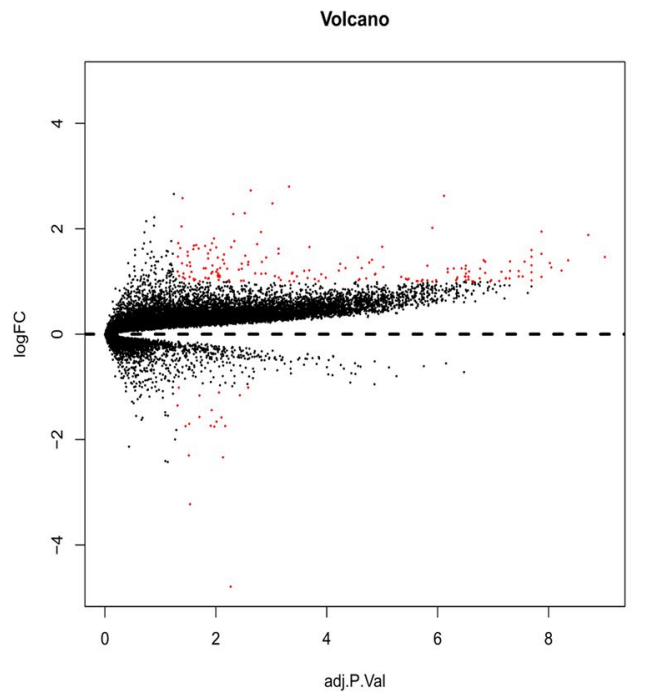

Fig. 1 A Heat map for the differentially expressed genes (DEGs). B Volcano plots reflecting number, significance and reliability of differentially expressed mRNA in NB. The red dots indicate dysregulated mRNAs 


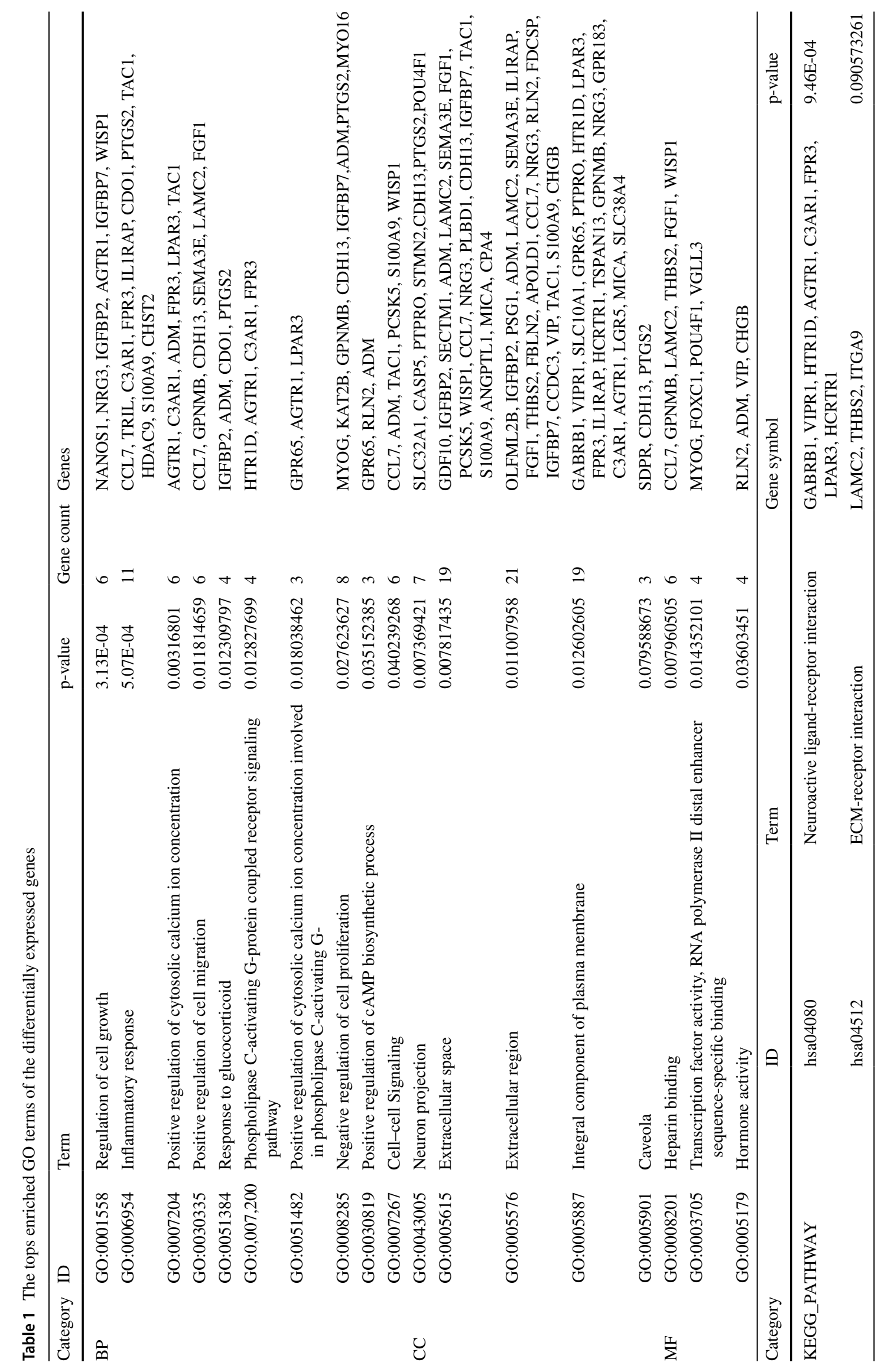



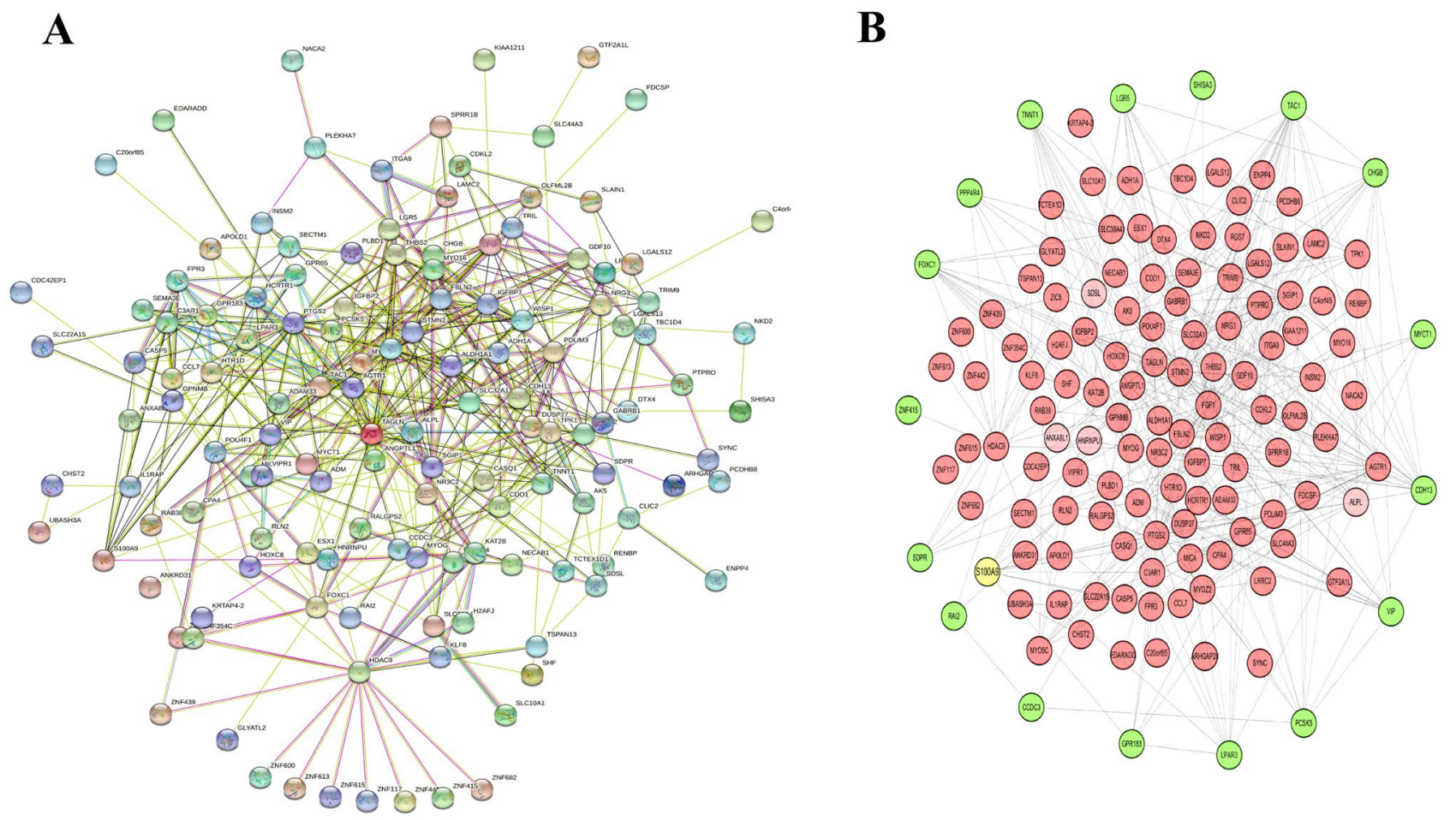

Fig. 2 A Protein-protein interaction network constructed with the dysregulated differentially expressed genes. B PPI network was visualized by Cystoscope software

between the $9 \mathrm{NB}$ patients with bone marrow metastasis and $10 \mathrm{NB}$ patients without bone marrow metastasis (Fig. 3A). Next, ELISA and IHC were performed to detect the protein levels of S100A9 in NB patients (9 NB patients with bone marrow metastasis and $10 \mathrm{NB}$ patients without bone marrow metastasis). The serum levels of S100A9 were higher from NB patients with bone marrow metastasis than without bone marrow metastasis (Fig. 3B). Further, IHC staining was also used to examined the expression of S100A9 from NB patients' tissues with and without bone marrow metastasis (Fig. 3C). The results showed that the expression levels of S100A9 were significantly higher in NB patients with bone marrow metastasis than NB patients without bone marrow metastasis.

\section{S100A9 overexpression promoted the proliferation, migration and invasion of NB cells}

To investigate the effects of $S 100 A 9$ on the proliferation of NB cells, the coding sequence of human S100A9 gene expressed in GST-S100A9 vector was subcloned into the SBI-piggyBac plasmid to overexpress S100A9 in SH-SY5Y cells. According to the MTT assay results, the SH-SY5Y cells overexpressing S100A9 (defined as the S100A9 group) exhibited higher proliferation ability than the SH-SY5Y cells transfected with empty vector (defined as the control group) at days 3, 4, and $5(\mathrm{p}<0.05)$. The S100A9-knockdown SHSY5Y cells (defined as the siS100A9 group) exhibited significantly slower proliferation when compared with the control group at days 3,4 , and 5 ( $\mathrm{p}<0.001)$ (Fig. 4A). Colony formation assay showed that the S100A9 group formed more colonies compared with the control group. Quantitatively, the number of colonies formed in the S100A9 group was approximately double than that of the control group (Fig. 4B). These results indicated that S100A9 overexpression accelerated the proliferation of SH-SY5Y cells. In addition, as revealed by wound healing and transwell assays, the results exhibited that the migration and invasion of $\mathrm{SH}$ SY5Y cells were significantly active by S100A9 (Fig. 4A and $B)$.

\section{Discussion}

High-throughput genome sequencing technologies have been widely used nowadays. Using these technologies, several research groups have identified genetic variations in human NB patients [22]. Among the identified genetic variations, MYCN amplification (32.1\%), 11q loss $(47.5 \%)$ and $17 \mathrm{q}$ gain $(80.4 \%)$ were the most frequently observed ones (around $90 \%$ in total) in individuals with a high risk of developing NB [23]. Furthermore, two research 
groups found that recurrent genomic rearrangements affecting genomic regions close to the telomerase reverse transcriptase (TERT) gene locus led to significant transcriptional upregulation of TERT [24, 25]. However, even though great progresses have been made in understanding the genetic basis of NB tumor occurrence and development, effective biomarkers for prediction of metastasis in NB patients are still lacking.

In the current study, the GSE90121 dataset which was deposited by David Kaplan were downloaded and analyzed by bioinformatics method to identify potential crucial genes associated with NB metastasis. A total of 195 genes including 19 down-regulated and 176 upregulated genes were obtained. Besides, the significantly enriched GO terms were mainly focused in regulation of cell growth, inflammatory response, positive regulation of cell migration. Hub genes of the regulatory network were then selected and conducted with PPI network module. Dysregulated TAC1, PTGS2 and FGF1 were the top three outstanding genes based on both six methods (Closeness, Degree, EPC, MNC, Radiality, and Stress centrality) evaluation. The expression levels of TAC1, PTGS2 and $F G F 1$ in resected specimen of NB patients with or without metastasis were then validated by qRT-PCR. Although the expression of TAC1, PTGS2 and FGF1 were related with many kinds of tumorigenesis, such as non-small cell lung cancer, pancreatic ductal cancer, colorectal cancer, squamous cell carcinoma, gastric cancer and clear cell renal cell carcinoma[26-33], but these genes expression did not exhibit significant change as expected as the microarray results, indicating that these three genes may not the pivotal gene that participate in the metastasis of NB.

After go through the differentially expressed genes list and reviewing the relevant literatures, we found that S100A9 exhibits a broad range of biological functions involving in various cancer progression [34-36]. Characterized by calcium-binding EF hand motifs, S100 family comprise of more than 20 homologous proteins. Studies have revealed that S100A9 induced activation of NF-kB which participate in a broad range of intracellular and extracellular functions by regulating angiogenesis, tumor migration, wound healing, cell apoptosis, proliferation, differentiation, and inflammation [9, 37-42]. In addition, it has become increasingly evident that S100A9 acts as a potent amplifier of inflammation in tumor. S100A9 have been reported to be as Damageassociated molecular patterns (DAMPs) and involved in almost all aspects of cancer biology, such as proliferation, tumorigenesis, apoptosis, invasion, metastasis and angiogenesis. To our knowledge, fewer researches investigated the expression and biological function of S100A9 in NB. In the present study, the promoted expression levels of S100A9 
A

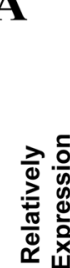

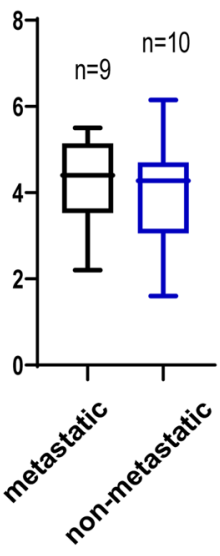

TAC1

C

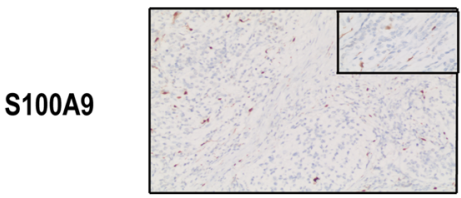

Ki67

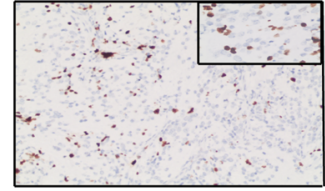

non-metastatic NB

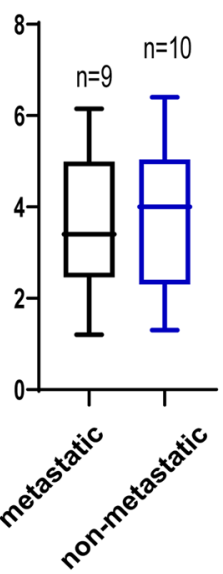

FGF1

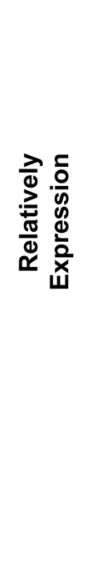

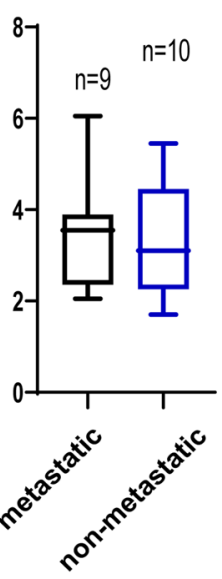

PTGS2
B

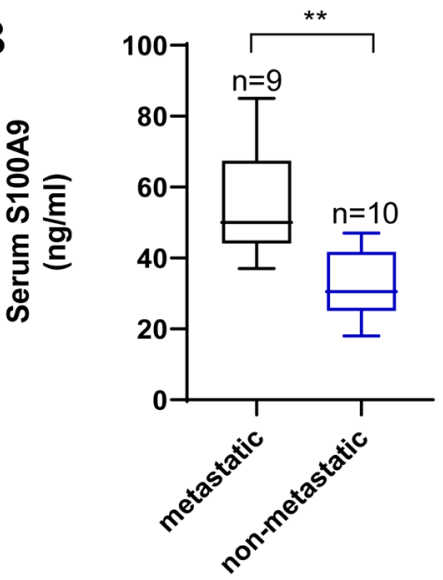

D
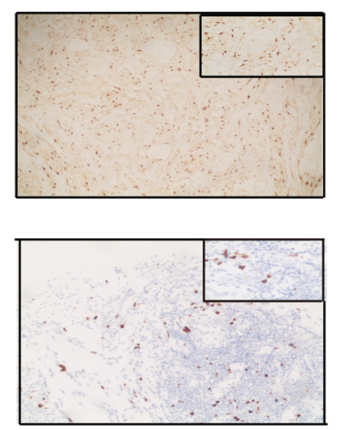

metastatic NB

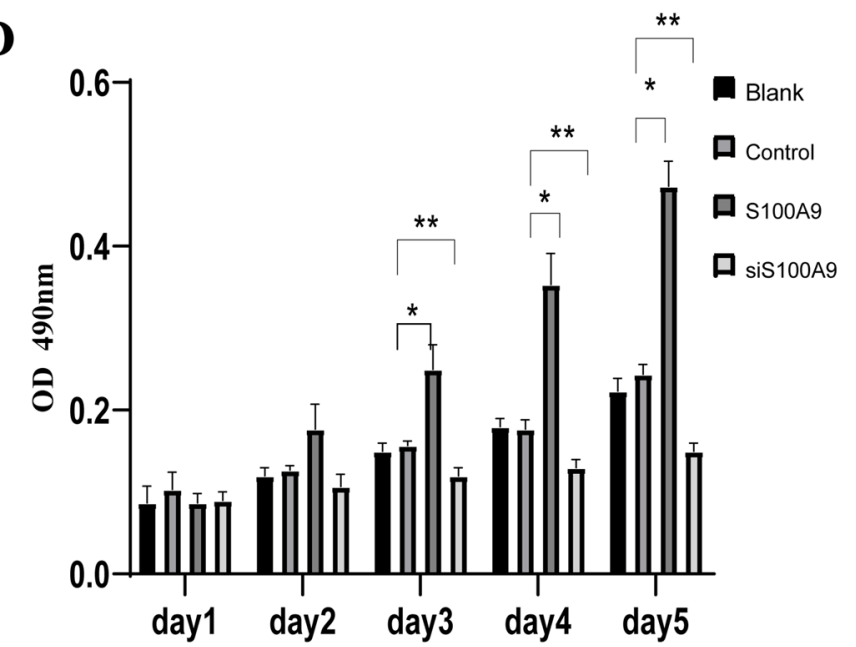

Fig. 3 A qRT-PCR analysis for the expression of hub genes. B ELISA analysis for serum levels of S100A9 in metastatic $(n=9)$ and non-metastatic NB $(n=10)$ patients. C Representative IHC staining for S100A9 in tissue sections from metastatic and non-metastatic NB

patients. **p $<0.01$. D MTT analysis for Blank/Control/S100A9/ siS100A9 SH-SY-5Y cells for sequential 5 days. *p $<0.05$, **p $<$ 0.01 .

elevated S100A9 promoted the proliferation and migration of NB cancer cells. 
A

a

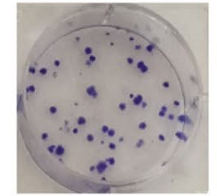

Control

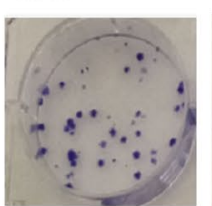

Blank

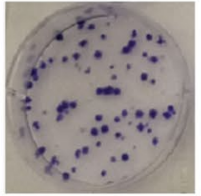

S100A9

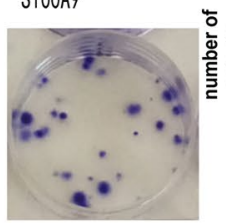

Si-S100A9
B
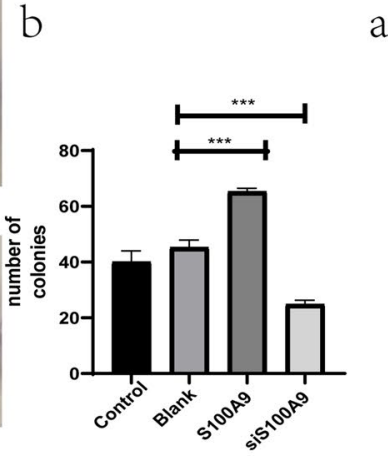

$\mathrm{a}$

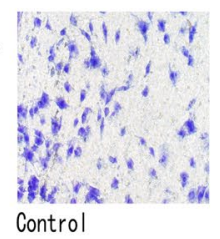

Control

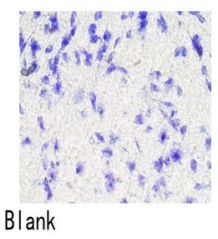

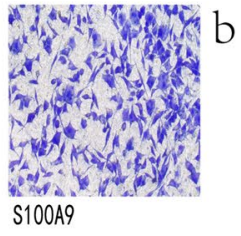

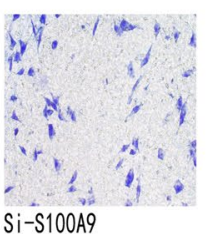

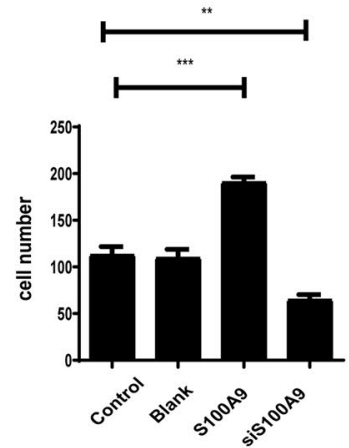

C

a

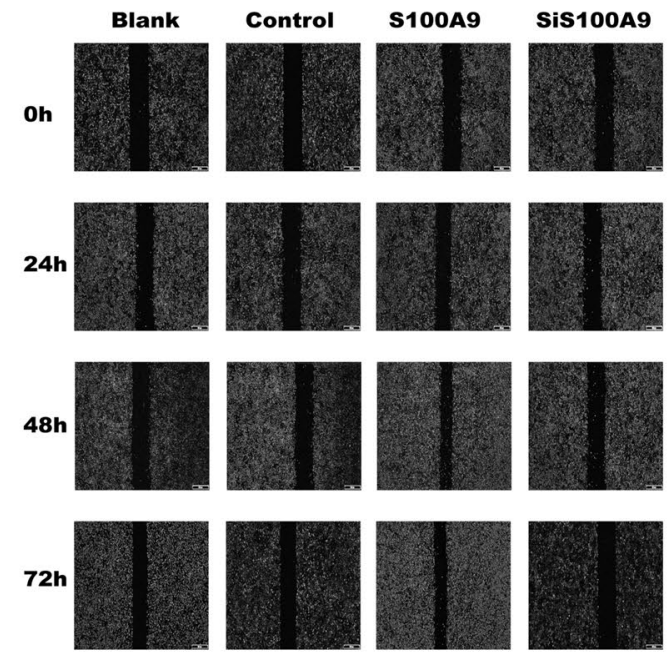

Fig. $4 \mathrm{~A}$ a. Colony formation assay for Blank/Control/S100A9/ siS100A9 SH-SY-5Y cells. b. The representative images of transmembrane cells are shown in the right panel. The mean numbers of transmembrane cells \pm SD per microscopic field of three independent experiments are quantified in the right panel. $* * \mathrm{p}<0.01$, $* * * \mathrm{p}<0.001$. B a.Transwell invasion assay for Blank/Control/ S100A9/siS100A9 SH-SY-5Y cells for $24 \mathrm{~h}$. b.The representative images of transmembrane cells are shown in the right panel. The

\section{Conclusions}

In conclusion, the current observations indicate that S100A9 may be an important carcinogenic factor in the occurrence and progression of NB and may serve as a promising biomarker for metastasis prediction of NB patients. Nevertheless, well designed and multi-ethnics clinical researches with large sample will be necessary to verify and strengthen the metastatic role of S100A9 in NB patients.

Acknowledgements We thank Professor Yan Xiao who kindly provided SH-SY-5Y cells.

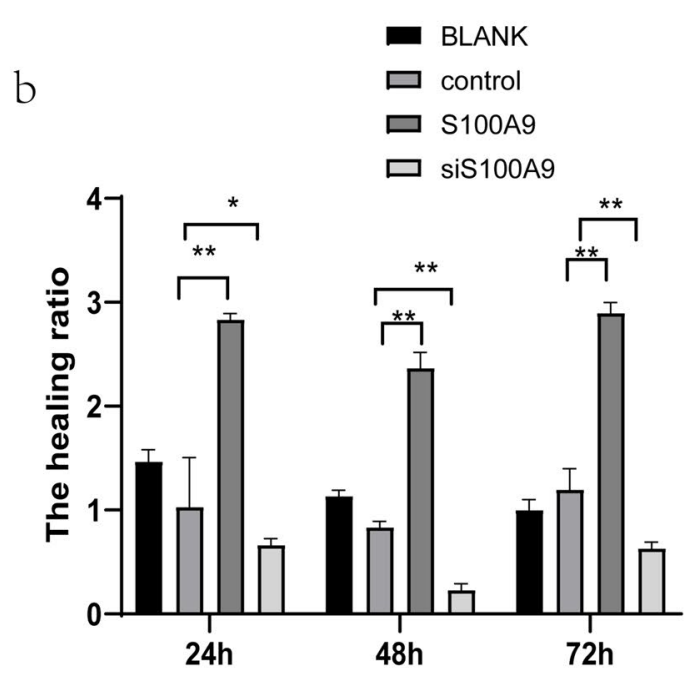

mean numbers of transmembrane cells \pm SD per microscopic field of three independent experiments are quantified in the right panel. Magnification, $\times 100, * * \mathrm{p}<0.01, * * * \mathrm{p}<0.001$. C a.Wound healing assay for Blank/Control/S100A9/siS100A9 SH-SY-5Y cells for 72 h. b.The incision width of different sites was measured and average healing rate was calculated and shown in the right panel. ${ }^{*} \mathrm{p}<0.05$, $* * \mathrm{p}<0.01$

Author contributions YYZ conceived the study. XC, YKX, JF, QWT and QW perform the study. Statistical analysis was undertaken by XC. All authors read and approved the final version of the manuscript. QW and YYZ wrote the manuscript.

Funding This study is fully supported by the National Natural Science Foundation of China (No. 81601821 to YYZ), the Natural Science Foundation of Shandong Province (No. ZR201910230488 to XC and No. ZR202102180776 to YYZ), China Postdoctoral Science Foundation (No. 2016M592144 to XC and No. 2016M590621 to YYZ), Postdoctoral innovation project of Shandong Province (No. 201603069 to YYZ), Shangdong Province Key Research and Development Program (2019GSF108108 to QW).

Data availability The following information was supplied regarding data availability: The data is available at NCBI GEO: GSE90121. 


\section{Declarations}

Conflict of interest All authors declare that they have no conflict of interest.

Ethical approval This study was approved by the Medical Ethics Committee of the Affiliated Hospital of Qingdao University.

Consent to participate Informed consent were obtained from the participants or their parents.

Consent for publication All authors had gone over the manuscript and consent to submit.

Open Access This article is licensed under a Creative Commons Attribution 4.0 International License, which permits use, sharing, adaptation, distribution and reproduction in any medium or format, as long as you give appropriate credit to the original author(s) and the source, provide a link to the Creative Commons licence, and indicate if changes were made. The images or other third party material in this article are included in the article's Creative Commons licence, unless indicated otherwise in a credit line to the material. If material is not included in the article's Creative Commons licence and your intended use is not permitted by statutory regulation or exceeds the permitted use, you will need to obtain permission directly from the copyright holder. To view a copy of this licence, visit http://creativecommons.org/licenses/by/4.0/.

\section{References}

1. Maris JM (2010) Recent advances in neuroblastoma. N Engl J Med 362:2202-2211. https://doi.org/10.1056/NEJMra0804577

2. Brignole C, Bensa V, Fonseca NA, Del Zotto G, Bruno S, Cruz AF, Malaguti F, Carlini B, Morandi F, Calarco E, Perri P, Moura V, Emionite L, Cilli M, De Leonardis F, Tondo A, Amoroso L, Conte M, Garaventa A, Sementa AR, Corrias MV, Ponzoni M, Moreira JN, Pastorino F (2021) Cell surface nucleolin represents a novel cellular target for neuroblastoma therapy. J Exp Clin Cancer Res 40:180. https://doi.org/10.1186/s13046-021-01993-9

3. Matthay KK, Maris JM, Schleiermacher G, Nakagawara A, Mackall CL, Diller L, Weiss WA (2016) Neuroblastoma. Nat Rev Dis Primers 2:16078. https://doi.org/10.1038/nrdp.2016.78

4. Hermani A, Hess J, De Servi B, Medunjanin S, Grobholz R, Trojan L, Angel P, Mayer D (2005) Calcium-binding proteins S100A8 and S100A9 as novel diagnostic markers in human prostate cancer. Clin Cancer Res 11:5146-5152. https://doi.org/10.1158/10780432.CCR-05-0352

5. Wagner NB, Weide B, Gries M, Reith M, Tarnanidis K, Schuermans V, Kemper C, Kehrel C, Funder A, Lichtenberger R, Sucker A, Herpel E, Holland-Letz T, Schadendorf D, Garbe C, Umansky V, Utikal J, Gebhardt C (2019) Tumor microenvironmentderived S100A8/A9 is a novel prognostic biomarker for advanced melanoma patients and during immunotherapy with anti-PD-1 antibodies. J Immunother Cancer 7:343. https://doi.org/10.1186/ s40425-019-0828-1

6. Aberg AM, Bergstrom SH, Thysell E, Tjon-Kon-Fat LA, Nilsson JA, Widmark A, Thellenberg-Karlsson C, Bergh A, Wikstrom P, Lundholm M (2021) High monocyte count and expression of S100A9 and S100A12 in peripheral blood mononuclear cells are associated with poor outcome in patients with metastatic prostate cancer. Cancers (Basel). https://doi.org/10.3390/cancers13102424

7. Tidehag V, Hammarsten P, Egevad L, Granfors T, Stattin P, Leanderson T, Wikstrom P, Josefsson A, Hagglof C, Bergh A (2014) High density of S100A9 positive inflammatory cells in prostate cancer stroma is associated with poor outcome. Eur J Cancer 50:1829-1835. https://doi.org/10.1016/j.ejca.2014.03.278

8. De Veirman K, De Beule N, Maes K, Menu E, De Bruyne E, De Raeve H, Fostier K, Moreaux J, Kassambara A, Hose D, Heusschen R, Eriksson H, Vanderkerken K, Van Valckenborgh E (2017) Extracellular S100A9 protein in bone marrow supports multiple myeloma survival by stimulating angiogenesis and cytokine secretion. Cancer Immunol Res 5:839-846. https:// doi.org/10.1158/2326-6066.CIR-17-0192

9. Laouedj M, Tardif MR, Gil L, Raquil MA, Lachhab A, Pelletier M, Tessier PA, Barabe F (2017) S100A9 induces differentiation of acute myeloid leukemia cells through TLR4. Blood 129:1980-1990. https://doi.org/10.1182/blood-2016-09-738005

10. Wang T, Du G, Wang D (2021) The S100 protein family in lung cancer. Clin Chim Acta. https://doi.org/10.1016/j.cca.2021.05. 028

11. Zheng S, Liu L, Xue T, Jing C, Xu X, Wu Y, Wang M, Xie X, Zhang B (2021) Comprehensive analysis of the prognosis and correlations with immune infiltration of S100 protein family members in hepatocellular carcinoma. Front Genet 12:648156. https://doi.org/10.3389/fgene.2021.648156

12. Mondet J, Chevalier S, Mossuz P (2021) Pathogenic roles of S100A8 and S100A9 proteins in acute myeloid and lymphoid leukemia: clinical and therapeutic impacts. Molecules. https:// doi.org/10.3390/molecules26051323

13. Liu L, Liu S, Deng P, Liang Y, Xiao R, Tang LQ, Chen J, Chen QY, Guan P, Yan SM, Huang X, Hong JH, Chen J, Sun Y, Teh BT, Yu Q, Mai HQ, Tan J (2021) Targeting the IRAK1-S100A9 axis overcomes resistance to paclitaxel in nasopharyngeal carcinoma. Cancer Res 81:1413-1425. https://doi.org/10.1158/ 0008-5472.CAN-20-2125

14. Seong BK, Fathers KE, Hallett R, Yung CK, Stein LD, Mouaaz S, Kee L, Hawkins CE, Irwin MS, Kaplan DR (2017) A metastatic mouse model identifies genes that regulate neuroblastoma metastasis. Cancer Res 77:696-706. https://doi.org/10.1158/ 0008-5472.CAN-16-1502

15. Ritchie ME, Phipson B, Wu D, Hu Y, Law CW, Shi W, Smyth GK (2015) Limma powers differential expression analyses for RNA-sequencing and microarray studies. Nucleic Acids Res 43:e47. https://doi.org/10.1093/nar/gkv007

16. da Huang W, Sherman BT, Lempicki RA (2009) Systematic and integrative analysis of large gene lists using DAVID bioinformatics resources. Nat Protoc 4:44-57. https://doi.org/10.1038/ nprot.2008.211

17. Szklarczyk D, Franceschini A, Wyder S, Forslund K, Heller D, Huerta-Cepas J, Simonovic M, Roth A, Santos A, Tsafou KP, Kuhn M, Bork P, Jensen LJ, von Mering C (2015) STRING v10: protein-protein interaction networks, integrated over the tree of life. Nucleic Acids Res 43:D447-452. https://doi.org/10.1093/ nar/gku1003

18. Shannon P, Markiel A, Ozier O, Baliga NS, Wang JT, Ramage D, Amin N, Schwikowski B, Ideker T (2003) Cytoscape: a software environment for integrated models of biomolecular interaction networks. Genome Res 13:2498-2504. https://doi. org/10.1101/gr. 1239303

19. Cesaro A, Anceriz N, Plante A, Page N, Tardif MR, Tessier PA (2012) An inflammation loop orchestrated by S100A9 and calprotectin is critical for development of arthritis. PLoS ONE 7:e45478. https://doi.org/10.1371/journal.pone.0045478

20. Luu HH, Zhou L, Haydon RC, Deyrup AT, Montag AG, Huo D, Heck R, Heizmann CW, Peabody TD, Simon MA, He TC (2005) Increased expression of S100A6 is associated with decreased metastasis and inhibition of cell migration and anchorage independent growth in human osteosarcoma. Cancer Lett 229:135148. https://doi.org/10.1016/j.canlet.2005.02.015 
21. Duan L, Wu R, Zhang X, Wang D, You Y, Zhang Y, Zhou L, Chen W (2018) HBx-induced S100A9 in NF-kappaB dependent manner promotes growth and metastasis of hepatocellular carcinoma cells. Cell Death Dis 9:629. https://doi.org/10.1038/ s41419-018-0512-2

22. Tsubota S, Kadomatsu K (2018) Origin and initiation mechanisms of neuroblastoma. Cell Tissue Res. https://doi.org/10.1007/ s00441-018-2796-z

23. Pugh TJ, Morozova O, Attiyeh EF, Asgharzadeh S, Wei JS, Auclair D, Carter SL, Cibulskis K, Hanna M, Kiezun A, Kim J, Lawrence MS, Lichenstein L, McKenna A, Pedamallu CS, Ramos AH, Shefler E, Sivachenko A, Sougnez C, Stewart C, Ally A, Birol I, Chiu R, Corbett RD, Hirst M, Jackman SD, Kamoh B, Khodabakshi AH, Krzywinski M, Lo A, Moore RA, Mungall KL, Qian J, Tam A, Thiessen N, Zhao Y, Cole KA, Diamond M, Diskin SJ, Mosse YP, Wood AC, Ji L, Sposto R, Badgett T, London WB, Moyer Y, Gastier-Foster JM, Smith MA, Guidry Auvil JM, Gerhard DS, Hogarty MD, Jones SJ, Lander ES, Gabriel SB, Getz G, Seeger RC, Khan J, Marra MA, Meyerson M, Maris JM (2013) The genetic landscape of high-risk neuroblastoma. Nat Genet 45:279-284. https://doi.org/10.1038/ng.2529

24. Peifer M, Hertwig F, Roels F, Dreidax D, Gartlgruber M, Menon R, Kramer A, Roncaioli JL, Sand F, Heuckmann JM, Ikram F, Schmidt R, Ackermann S, Engesser A, Kahlert Y, Vogel W, Altmuller J, Nurnberg P, Thierry-Mieg J, Thierry-Mieg D, Mariappan A, Heynck S, Mariotti E, Henrich KO, Gloeckner C, Bosco G, Leuschner I, Schweiger MR, Savelyeva L, Watkins SC, Shao C, Bell E, Hofer T, Achter V, Lang U, Theissen J, Volland R, Saadati M, Eggert A, de Wilde B, Berthold F, Peng Z, Zhao C, Shi L, Ortmann M, Buttner R, Perner S, Hero B, Schramm A, Schulte JH, Herrmann C, O'Sullivan RJ, Westermann F, Thomas RK, Fischer $M$ (2015) Telomerase activation by genomic rearrangements in high-risk neuroblastoma. Nature 526:700-704. https://doi.org/10. 1038/nature14980

25. Valentijn LJ, Koster J, Zwijnenburg DA, Hasselt NE, van Sluis P, Volckmann R, van Noesel MM, George RE, Tytgat GA, Molenaar JJ, Versteeg R (2015) TERT rearrangements are frequent in neuroblastoma and identify aggressive tumors. Nat Genet 47:14111414. https://doi.org/10.1038/ng.3438

26. Liu B, Ricarte Filho J, Mallisetty A, Villani C, Kottorou A, Rodgers K, Chen C, Ito T, Holmes K, Gastala N, Valyi-Nagy K, David O, Gaba RC, Ascoli C, Pasquinelli M, Feldman LE, Massad MG, Wang TH, Jusue-Torres I, Benedetti E, Winn RA, Brock MV, Herman JG, Hulbert A (2020) Detection of promoter DNA methylation in urine and plasma aids the detection of non-small cell lung cancer. Clin Cancer Res 26:4339-4348. https://doi.org/10.1158/ 1078-0432.CCR-19-2896

27. Maekawa H, Ito T, Orita H, Kushida T, Sakurada M, Sato K, Hulbert A, Brock MV (2020) Analysis of the methylation of $\mathrm{CpG}$ islands in the CDO1, TAC1 and CHFR genes in pancreatic ductal cancer. Oncol Lett 19:2197-2204. https://doi.org/10.3892/ ol.2020.11340

28. Ma Z, Williams M, Cheng YY, Leung WK (2019) Roles of methylated DNA biomarkers in patients with colorectal cancer. Dis Markers 2019:2673543. https://doi.org/10.1155/2019/2673543

29. Kunzmann AT, Murray LJ, Cardwell CR, McShane CM, McMenamin UC, Cantwell MM (2013) PTGS2 (Cyclooxygenase-2) expression and survival among colorectal cancer patients: a systematic review. Cancer Epidemiol Biomarkers Prev 22:14901497. https://doi.org/10.1158/1055-9965.EPI-13-0263

30. Vene R, Costa D, Augugliaro R, Carlone S, Scabini S, Casoni Pattacini G, Boggio M, Zupo S, Grillo F, Mastracci L, Pitto F, Minghelli S, Ferrari N, Tosetti F, Romairone E, Mingari MC, Poggi A, Benelli R (2020) Evaluation of glycosylated PTGS2 in colorectal cancer for NSAIDS-based adjuvant therapy. Cells. https://doi.org/ 10.3390/cells 9030683
31. Shintani T, Higaki M, Okamoto T (2021) Heparin-binding protein 17/Fibroblast growth factor-binding protein-1 knockout inhibits proliferation and induces differentiation of squamous cell carcinoma cells. Cancers (Basel). https://doi.org/10.3390/cancers131 12684

32. Zhang J, Zhang J, Pang X, Chen Z, Zhang Z, Lei L, Xu H, Wen L, Zhu J, Jiang Y, Cui Y, Chen G, Wang X (2021) MiR-205-5p suppresses angiogenesis in gastric cancer by down regulating the expression of VEGFA and FGF1. Exp Cell Res 404:112579. https://doi.org/10.1016/j.yexcr.2021.112579

33. Zhang X, Wang Z, Zeng Z, Shen N, Wang B, Zhang Y, Shen $\mathrm{H}$, Lu W, Wei R, Ma W, Wang C (2021) Bioinformatic analysis identifying FGF1 gene as a new prognostic indicator in clear cell renal cell carcinoma. Cancer Cell Int 21:222. https://doi.org/10. 1186/s12935-021-01917-9

34. Wu R, Duan L, Cui F, Cao J, Xiang Y, Tang Y, Zhou L (2015) S100A9 promotes human hepatocellular carcinoma cell growth and invasion through RAGE-mediated ERK1/2 and p38 MAPK pathways. Exp Cell Res 334:228-238. https://doi.org/10.1016/j. yexcr.2015.04.008

35. Duan L, Wu R, Ye L, Wang H, Yang X, Zhang Y, Chen X, Zuo G, Zhang Y, Weng Y, Luo J, Tang M, Shi Q, He T, Zhou L (2013) S100A8 and S100A9 are associated with colorectal carcinoma progression and contribute to colorectal carcinoma cell survival and migration via Wnt/beta-catenin pathway. PLoS ONE 8:e62092. https://doi.org/10.1371/journal.pone.0062092

36. Chen KT, Kim PD, Jones KA, Devarajan K, Patel BB, Hoffman JP, Ehya H, Huang M, Watson JC, Tokar JL, Yeung AT (2014) Potential prognostic biomarkers of pancreatic cancer. Pancreas 43:22-27. https://doi.org/10.1097/MPA.0b013e3182a6867e

37. Lee JS, Lee NR, Kashif A, Yang SJ, Nam AR, Song IC, Gong SJ, Hong MH, Kim G, Seok PR, Lee MS, Sung KH, Kim IS (2020) S100A8 and S100A9 promote apoptosis of chronic eosinophilic leukemia cells. Front Immunol 11:1258. https://doi.org/10.3389/ fimmu.2020.01258

38. Zha H, Li X, Sun H, Duan L, Yuan S, Li H, Li A, Gu Y, Zhao J, Xie J, Zhou L (2019) S100A9 promotes the proliferation and migration of cervical cancer cells by inducing epithelialmesenchymal transition and activating the $\mathrm{Wnt} /$ betacatenin pathway. Int J Oncol 55:35-44. https://doi.org/10.3892/ijo.2019.4793

39. Li Y, Kong F, Jin C, Hu E, Shao Q, Liu J, He D, Xiao X (2019) The expression of S100A8/S100A9 is inducible and regulated by the Hippo/YAP pathway in squamous cell carcinomas. BMC Cancer 19:597. https://doi.org/10.1186/s12885-019-5784-0

40. Schneider RK, Schenone M, Ferreira MV, Kramann R, Joyce CE, Hartigan C, Beier F, Brummendorf TH, Germing U, Platzbecker U, Busche G, Knuchel R, Chen MC, Waters CS, Chen E, Chu LP, Novina CD, Lindsley RC, Carr SA, Ebert BL (2016) Rps14 haploinsufficiency causes a block in erythroid differentiation mediated by S100A8 and S100A9. Nat Med 22:288-297. https://doi.org/10. 1038/nm.4047

41. Tian Y, Cao R, Che B, Sun D, Tang Y, Jiang L, Bai Q, Liu Y, Morozova-Roche LA, Zhang C (2020) Proinflammatory S100A9 regulates differentiation and aggregation of neural stem cells. ACS Chem Neurosci 11:3549-3556. https://doi.org/10.1021/acsch emneuro.0c00365

42. Marinkovic G, Koenis DS, de Camp L, Jablonowski R, Graber $\mathrm{N}$, de Waard V, de Vries CJ, Goncalves I, Nilsson J, Jovinge S, Schiopu A (2020) S100A9 links inflammation and repair in myocardial infarction. Circ Res 127:664-676. https://doi.org/10.1161/ CIRCRESAHA.120.315865

Publisher's Note Springer Nature remains neutral with regard to jurisdictional claims in published maps and institutional affiliations. 